\title{
Chitosan Imparts Better Biological Properties for Poly( $\varepsilon$-caprolactone) Electrospun Membranes than Dexamethasone
}

\author{
Bruno R. Machado, ${ }^{a}$ Sharise B. Roberto, ${ }^{\circledR *, a}$ Elton G. Bonafé, ${ }^{a}$ Samira E. A. Camargo, ${ }^{b, c}$ \\ Carlos H. R. Camargo, ${ }^{b, c}$ Ketul C. Popat, ${ }^{b}$ Matt J. Kipper ${ }^{d}$ and Alessandro F. Martins ${ }^{*, a, d}$
}

${ }^{a}$ Laboratório de Materiais, Macromoléculas e Compósitos,
Universidade Tecnológica Federal do Paraná(UTFPR), 86812-460 Apucarana-PR, Brazil

${ }^{b}$ Department of Mechanical Egineering, Chemical and Biological Engineering, School of Biomedical Engineering, Colorado State University, 80523 Fort Collins CO, USA

${ }^{c}$ College of Dentistry and Department of Restorative Dental Sciences, University of Florida, 32603 Gainesville FL, USA

${ }^{d}$ Department of Chemical and Biological Engineering, Colorado State University, 1370 Campus Delivery, 80523 Fort Collins CO, USA

\begin{abstract}
Poly( $\varepsilon$-caprolactone), an aliphatic polyester with biodegradability and cytocompatibility, has been used to create scaffolds for tissue engineering purposes. However, the hydrophobicity and low water absorptivity of poly( $\varepsilon$-caprolactone) reduce cell anchorage on their membranes. Here, poly( $\varepsilon$-caprolactone)-based scaffolds were prepared by electrospinning of poly( $\varepsilon$-caprolactone)chitosan blend, and poly( $\varepsilon$-caprolactone)-dexamethasone solution. Chitosan and dexamethasone play an essential role to increase the scaffolding performance of poly( $\varepsilon$-caprolactone)-based electrospun membranes. A poly( $\varepsilon$-caprolactone) membrane without chitosan and dexamethasone did not provide satisfactory results to promote cell culture of adipose mesenchymal stem cells (AMSCs). Compared to the poly( $\varepsilon$-caprolactone)-dexamethasone surface, poly( $\varepsilon$-caprolactone)chitosan membrane imparts better cytoskeletal reorganization, and cell spreading, increasing the strength of cell attachment. Also, poly( $\varepsilon$-caprolactone)-chitosan composite provides strong antimicrobial activity against Pseudomonas aeruginosa (ca. $90 \%$ inhibition). Therefore, the poly( $\varepsilon$-caprolactone)-chitosan composite is a better alternative to treat skin diseases and promote skin regeneration than conventional approaches based on dexamethasone.
\end{abstract}

Keywords: antimicrobial activity, cytotoxicity, cell adhesion, scaffolds, electrospinning

\section{Introduction}

Poly( $\varepsilon$-caprolactone) has been used to develop cytocompatible materials for tissue engineering due to its suitable mechanical properties, biodegradability, and affinity to biological tissues. ${ }^{1}$ Poly( $\varepsilon$-caprolactone)-based nanofibers produced via electrospinning have received significant attention because they present large surface area to volume ratio, aiming repair of skin tissues and skin diseases. ${ }^{2}$ However, it is a challenge to yield suitable poly( $\varepsilon$-caprolactone)-based biomaterials for tissue engineering purposes because poly( $\varepsilon$-caprolactone) has high hydrophobicity and low water adsorption. ${ }^{3}$ Therefore, poly( $\varepsilon$-caprolactone) should be blended to polysaccharides

*e-mail: sharise_beatriz@hotmail.com; afmartins@utfpr.edu.br (chitosan, ${ }^{2}$ cellulose acetate, ${ }^{4}$ and starch $^{5}$ ) or associated to materials with biological properties such as dexamethasone (notable for its anti-inflammatory properties) ${ }^{6,7}$ to produce electrospun membranes for applications in tissue engineering field. These materials can enhance the cytocompatibility, promoting better anchorage of cells onto poly( $\varepsilon$-caprolactone)-based membrane surfaces.

Chitosan is a linear polysaccharide, composed of randomly distributed $\beta(1 \rightarrow 4)$-D-glucosamine and $N$-acetylD-glucosamine units. ${ }^{8-10}$ Chitosan is an attractive candidate for forming blends with poly( $\varepsilon$-caprolactone), aiming production of poly( $\varepsilon$-caprolactone)-chitosan nanofibers. Poly( $\varepsilon$-caprolactone)-chitosan blends have been prepared in several solvent mixtures, such as acetic acid / formic acid, ${ }^{11}$ formic acid / acetone, ${ }^{12}$ acetic acid / water, ${ }^{2}$ trifluoroacetic acid / 2,2,2-trifluoroethanol, ${ }^{13}$ and others. Among these 
systems, acetic acid / formic acid solvent has promoted stable poly( $\varepsilon$-caprolactone)-chitosan nanofibers with smaller diameters than poly( $\varepsilon$-caprolactone)-chitosan membranes obtained in other solvents. ${ }^{11}$

Dexamethasone (1-dehydro-16 $\alpha$-methyl-9 $\alpha$-fluorohydrocortisone) is a synthetic glucocorticoid with antiinflammatory properties used in formulations containing antibiotics (e.g., gentamicin) to treat infectious diseases promoted by bacteria, such as Pseudomonas aeruginosa. ${ }^{14}$ P. aeruginosa is a Gram-negative microorganism responsible for bloodstream infections, pneumonia, and infections of skin and soft tissues. ${ }^{15}$ The acute external otitis disease is an infection of skin and subcutaneous tissues, commonly caused by P. aeruginosa and Staphylococcus aureus. ${ }^{16}$ Conventional treatment of otitis often involves administration of aminoglycosides (e.g., gentamicin) in combination with dexamethasone. ${ }^{16}$ However, a study has related that dexamethasone could suppress the antimicrobial activity of gentamicin (and other antibiotics) when both are simultaneously administered to treat infections promoted by $P$. aeruginosa and other pathogens..$^{14}$ Besides, the use of dexamethasone and gentamicin are limited because they promote side effects to the central nervous system ${ }^{17}$ and kidneys, ${ }^{18}$ respectively. Yet, dexamethasone causes insomnia, indigestion, weight gain, acne, and gain of appetite. ${ }^{19}$

The are some papers reporting about poly( $\varepsilon$-caprolactone)chitosan and poly( $\varepsilon$-caprolactone)-dexamethasone electrospun membranes. Poly( $\varepsilon$-caprolactone) is blended to chitosan to create scaffold electrospun membranes for supporting adhesion and proliferation of stem cells..$^{20,21}$ Poly( $\varepsilon$-caprolactone)-chitosan-polypyrrole nanofiber scaffolds supported the attachment, growth and spreading of neural cells. ${ }^{22}$ Chitosan has been used to improve the surface wettability of hydrophobic electrospun membranes. ${ }^{22}$ In this facet, poly( $\varepsilon$-caprolactone)-chitosan-hydroxyapatite composite membrane scaffolds promoted proliferation and osteogenic differentiation of human dental pulp stem cells. ${ }^{23}$ Poly( $\varepsilon$-caprolactone)-chitosan-based composite membranes have been used for wound healing, ${ }^{24,25}$ wound dressing, ${ }^{25}$ skin repair in burn wounds, ${ }^{26}$ cranial tissue regeneration, ${ }^{27}$ bladder regeneration, ${ }^{20}$ cartilage defect repair, ${ }^{28}$ and other applications. Vacanti et al. ${ }^{29}$ produced poly( $\varepsilon$-caprolactone) and poly(L-lactic)-poly( $\varepsilon$-caprolactone) nanofibers loaded with dexamethasone (5.7 wt.\% of dexamethasone relative to dexamethasone and polymer content). ${ }^{29}$ Controlled release of dexamethasone allowed tissue regeneration, as well as attachment and growth of human mesenchymal stem cells in vitro. ${ }^{29,30}$ Scaffolds based on poly( $\varepsilon$-caprolactone)poloxamine loaded with dexamethasone also promoted release of dexamethasone and, hence fostered bone regeneration. ${ }^{6}$ However, as suggested by many reports, dexamethasone must be avoided in real applications because of its disadvantages. ${ }^{17,18}$ In this paper, we are envisioning to compare the biological properties of poly( $\varepsilon$-caprolactone), poly( $\varepsilon$-caprolactone)-chitosan and poly( $\varepsilon$-caprolactone)dexamethasone and show that the chitosan can replace dexamethasone in tissue engineering purposes.

As suggested elsewhere, low contents of dexamethasone (5.0 to $6.0 \mathrm{wt} . \%$ ) can significantly improve the biomedical responses upon human stem cells. ${ }^{29,30}$ Current reports indicated that at least 20-30 wt.\% chitosan could be added to poly( $\varepsilon$-caprolactone) solutions for generating blends with good electrospinnability. ${ }^{11,22,31}$ Then, this study aims to produce poly( $\varepsilon$-caprolactone)-chitosan and poly( $\varepsilon$-caprolactone)-dexamethasone membranes using a low content of dexamethasone (5.0 wt.\%) and a high level of chitosan (20 wt.\%), respectively. Here, we are envisioning to compare the biological properties of poly(E-caprolactone), poly( $\varepsilon$-caprolactone)-chitosan and poly( $\varepsilon$-caprolactone)-dexamethasone scaffolds to promote attachment, adhesion, and proliferation of adipose-derived stem cells, and bactericidal activity against $P$. aeruginosa . So, poly ( $\varepsilon$-caprolactone)-chitosan scaffold membrane could replace conventional treatments of skin diseases promoted by the administration of dexamethasone and antibiotics, reducing side effects to the health.

\section{Experimental}

\section{Materials}

Poly ( $\varepsilon$-caprolactone) $\left(80,000 \mathrm{~g} \mathrm{~mol}^{-1}\right)$, dexamethasone (suitable for cell culture, $\geq 97 \%$ for high performance liquid chromatography (HPLC)), 1,1,1,3,3,3-hexafluoro2-propanol ( $\geq 99 \%)$, and formic acid ( $88 \%$ ) were purchased from Sigma-Aldrich (St. Louis, USA). Chitosan of $87 \times 10^{3} \mathrm{~g} \mathrm{~mol}^{-1}$ average molar weight and $85 \%$ deacetylated was purchased from Golden-Shell Biochemical (Yuhuan Country of Zhejiang Province, China). ${ }^{32,33}$ Acetic acid $(\geq 98 \%$ ) was obtained from Acros Organics (New Jersey, USA).

Forming poly( $\varepsilon$-caprolactone)-based membranes by electrospinning

Poly( $\varepsilon$-caprolactone) and poly( $\varepsilon$-caprolactone)dexamethasone membranes

The poly( $\varepsilon$-caprolactone) membrane is formed from a solution carried out in 1,1,1,3,3,3-hexafluoro2 -propanol at $12 \% \mathrm{~m} / \mathrm{v}$. For preparing poly( $\varepsilon$-caprolactone)dexamethasone nanofiber, powder dexamethasone is dissolved in methanol to reach $30 \mathrm{mg} \mathrm{mL}^{-1}$. This solution 
is added to $12 \% \mathrm{~m} / \mathrm{v}$ poly( $\varepsilon$-caprolactone) solution to reach 76/ 24 1,1,1,3,3,3-hexafluoro-2-propanol / methanol volume ratio, providing $5.0 \mathrm{wt} . \%$ of dexamethasone concerning the poly( $\varepsilon$-caprolactone) content. Both poly( $\varepsilon$-caprolactone) and poly( $\varepsilon$-caprolactone)-dexamethasone solutions $(5.0 \mathrm{~mL})$ were obtained in a vortex stirrer at room temperature for $1.0 \mathrm{~h}$. Poly( $\varepsilon$-caprolactone) and poly( $\varepsilon$-caprolactone)dexamethasone solutions were separately transferred to a $10 \mathrm{~mL}$ glass syringe and connected to an 18-gauge blunt stainless-steel needle charged by a high voltage direct current (DC) power supply (Gamma High Voltage Research) at $17 \mathrm{kV}\left(20 \pm 2{ }^{\circ} \mathrm{C}\right.$ and $22 \%$ relative humidity $) .{ }^{34}$ The tip to collector distance was set at $12.5 \mathrm{~cm}$, and the solutions are pumped $\left(2.5 \mathrm{~mL} \mathrm{~h}^{-1}\right)$ in a Kent Scientific Genie Plus (Torrington, USA) syringe pump. As-obtained poly( $\varepsilon$ caprolactone) and poly( $\varepsilon$-caprolactone)-dexamethasone membranes were characterized. Before cell culture and antimicrobial assays, these membranes were carefully added to deionized water and sterilized by ultraviolet irradiation (3 min). Poly( $\varepsilon$-caprolactone) electrospun membrane was called PCL, while the poly( $\varepsilon$-caprolactone)-dexamethasone was labeled as PCL-DEX.

\section{Poly( $\varepsilon$-caprolactone)-chitosan electrospun membrane}

The poly( $\varepsilon$-caprolactone)-chitosan nanofiber was obtained according to the methodology described by Van der Schueren et al. ${ }^{11}$ with modifications. The same apparatus used to produce the poly( $\varepsilon$-caprolactone)dexamethasone membrane was used here; however, poly( $\varepsilon$-caprolactone)-chitosan electrospun membrane is prepared from a blend performed at 70/30 acetic acid / formic acid mixture. The blend solution contains $20 \mathrm{wt} . \%$ chitosan concerning poly( $\varepsilon$-caprolactone) ( $80 \mathrm{wt} . \%)$. The blend is created by adding desirable chitosan content (powder) into the poly( $\varepsilon$-caprolactone) solution, which is initially prepared at $6.6 \% \mathrm{~m} / \mathrm{v}$ in $70 / 30$ acetic acid / formic acid mixture. The polymeric blend $(5.0 \mathrm{~mL})$ is also provided in a vortex apparatus at room temperature for $1.0 \mathrm{~h}$. Other parameters for electrospinning were: flow rate of $1.0 \mathrm{~mL} \mathrm{~h}^{-1}$, tip to collector distance of $12.5 \mathrm{~cm}$, and voltage of $15 \mathrm{kV}$. Before the characterization, poly( $\varepsilon$-caprolactone)-chitosan membrane is neutralized in a phosphate-buffered saline (PBS) buffer ( $\mathrm{pH} 7.4$ ) for $24 \mathrm{~h}$, changing the PBS five times (the first four exchanges were performed each $3 \mathrm{~h}$, and the last one was carried out after $12 \mathrm{~h}$ ). After neutralization, the membrane was rinsed with deionized water to remove PBS, frozen, and lyophilized (24 h). After neutralization, and before cell culture and antimicrobial tests, this material was also added to deionized water and sterilized by ultraviolet irradiation ( $3 \mathrm{~min})$. Poly( $\varepsilon$-caprolactone)chitosan membrane is called PCL-CS.

\section{Characterization}

The material surfaces are analyzed by scanning electron microscopy (SEM) by using a JEOL JSM-6700F apparatus (Tokyo, Japan). Fiber diameters are determined from SEM images (50 counts), using the ImageJ software..$^{35}$ The poly( $\varepsilon$-caprolactone)-based membranes were characterized through Fourier transform infrared spectroscopy (FTIR), using a Shimadzu FTIR-8300 (Shimadzu Scientific Instrument, Tokyo, Japan), ranging from 2000 to $600 \mathrm{~cm}^{-1}$ at $4 \mathrm{~cm}^{-1}$ resolution with 64 scans.

Surface chemistry of the membranes is analyzed by using a Phi Electronics 5800 Spectrometer (Chanhassen, USA). X-ray photoelectron spectroscopy (XPS) spectra are processed with a monochromatic $\mathrm{Al} \mathrm{K} \alpha \mathrm{X}$-ray source $(\mathrm{hv}=1486.6 \mathrm{eV})$, a hemispherical analyzer, and a multichannel detector. All spectra are yielded with a photoelectron take-off angle of $45^{\circ}$. A low-energy electron gun is applied for charge neutralization. The water contact angles (WCAs) are evaluated by analyzing static contact angles by the sessile drop method, using a contact angle goniometer (Krüss DSA 10, Hamburg, Germany), equipped with video capture. Images are captured every $1.0 \mathrm{~min}$ throughout $10 \mathrm{~min}$ by evaluating the contact of a droplet with the surfaces by a camera $(n=3)$.

\section{Dexamethasone release assay}

In vitro release assay of dexamethasone was carried out according to a previously reported methodology $y^{29}$ with some adaptations. As-obtained poly( $\varepsilon$-caprolactone)dexamethasone membrane (ca. $0.02 \mathrm{~g}$ ) in $20 \mathrm{~mL}$ of PBS (pH 7.4) was added to a shaker (Thoth 6430) under shaking (100 rpm) for few hours at $37{ }^{\circ} \mathrm{C}$. At desired time intervals, aliquots of the PBS medium are removed, and absorbance measurements are evaluated at ca. $240 \mathrm{~nm}$ in a UV-Vis spectrophotometer (Cary, São Paulo, Brazil). The concentration of dexamethasone was determined by using a dexamethasone standard curve performed with methanolic solutions ranging from 10 to $100 \mathrm{mg} \mathrm{mL}^{-1}$.

\section{Cell culture assays}

Before seeding the cells on the samples, the adiposederived mesenchymal stem cells (ADSC) are cultured according to the previous methodology reported by Martins et $a l .{ }^{34}$ (see Supplementary Information (SI) section).

\section{Cell viability studies}

Cell viability is determined by a CellTiter-Blue ${ }^{\circledR}$ cell 
viability assay (Promega G808A, Madison, USA) according to the manufacturer's instructions and a previously reported methodology. ${ }^{34}$ After 1 and 7 days, $50 \mu$ L CellTiter-Blue ${ }^{\circledR}$ dye is added to $500 \mu \mathrm{L}$ cell culture media containing the sample surfaces and incubated for $6 \mathrm{~h}\left(37^{\circ} \mathrm{C}\right)$ at $5 \% \mathrm{CO}_{2}$. The cell viability is determined in a UV-Vis microplate reader (Molecular Devices Spectra Max M3, Sunnyvale, USA) at 570 and $600 \mathrm{~nm}^{34}$

\section{Adhesion and proliferation assay}

The adhesion and proliferation assays are carried out according to the previous methodology described by Martins et $a l .{ }^{34}$ In brief, cell adhesion and proliferation tests are assessed by staining the cells with rhodamine phalloidin, 5-chloromethyl fluorescein diacetate (CMFDA; Life Technologies), and 4',6-diamidino-2-phenylindole (DAPI; Invitrogen) after 1 and 7 days of cell culture. ${ }^{34}$ The full procedure is described in the SI section.

\section{Cell morphology}

The attachment and morphology of the ADSC cells on the scaffold membranes were evaluated by SEM after 1 and 7 days of cell culture, according to the previous methodology $y^{36}$ (SI section). The SEM images are acquired by the same conditions reported in sub-section Characterization.

\section{Antimicrobial assay}

The antimicrobial assay is carried out according to the methodology reported by Martins et al. ${ }^{34}$ In brief, scaffold membranes (diameters of $6.0 \mathrm{~mm}$ ) are added to $500 \mu \mathrm{L}$ lysogeny and inoculated with $50 \mu \mathrm{L}$ P. aeruginosa culture in a 0.3 optical density at $600 \mathrm{~nm}$. After $24 \mathrm{~h}$, cell suspensions are removed, and trapped bacteria are stained with live / dead BacLight ${ }^{\mathrm{TM}}$ stains (Invitrogen) and then, cells are microscopically counted by using a Zeiss Axioskop2 epi-microscope apparatus at a 100× oil objective. ${ }^{34}$ The live / dead stain includes SYTO 9, that stains bacteria in population, and propidium iodide that may only penetrate bacteria having damaged membranes. An appropriate mixture of the SYTO 9 and propidium iodide promotes living cell membranes stain fluorescent green, whereas dead bacteria with damaged membranes stain fluorescent red. ${ }^{34}$ Live and dead bacteria were visualized and counted in identical surface locations, and the fluorescence images are used to determine the live and dead bacteria using Image J software ${ }^{35}$ by counting cells averaged over 5.0 random areas on each filter specimen $(\mathrm{n}=3)$.

\section{Statistical analysis}

The results are statistically analyzed by using analysis of variance (ANOVA) and Tukey's tests (GraphPad Prism 6.0), ${ }^{37}$ at a $5.0 \%$ significance level.

\section{Results and Discussion}

Characterization of poly( $\varepsilon$-caprolactone)-based electrospun membranes

Figure 1 shows SEM images of the PCL, PCL-DEX, and PCL-CS electrospun membranes. The PCL, PCL-DEX, and PCL-CS fibers presented diameters of $1.9 \pm 0.4 \mu \mathrm{m}$, $365 \pm 96$ and $306 \pm 86 \mathrm{~nm}$, respectively. These findings agreed with other reported results. Hild et al. ${ }^{38}$ prepared PCL-CS membranes with diameters ranging from 200 to $400 \mathrm{~nm},{ }^{38}$ while Van der Schueren et al. ${ }^{11}$ obtained smaller PCL-CS membranes (200 to $250 \mathrm{~nm}$ ). ${ }^{11}$ Considering poly( $\varepsilon$-caprolactone)-based membranes loaded with dexamethasone (5 to $20 \mathrm{wt}$ \% concerning the whole polymer content), Martins et al. ${ }^{30}$ reported nanofibers with diameters ranging from $150 \mathrm{~nm}$ to $1.6 \mu \mathrm{m} .{ }^{30}$

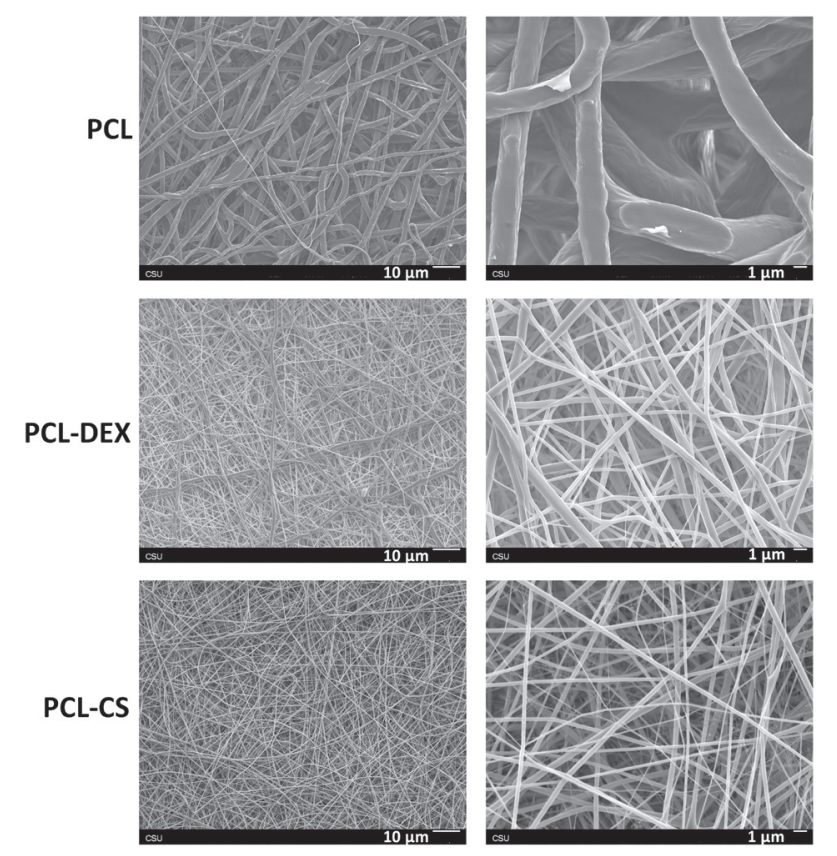

Figure 1. SEM images of the poly( $\varepsilon$-caprolactone)-based membranes: PCL, PCL-DEX, and neutralized PCL-CS.

PCL and PCL-DEX membranes were prepared from uniform solutions carried out in 1,1,1,3,3,3-hexafluoro2-propanol and 1,1,1,3,3,3-hexafluoro-2-propanol / methanol solvents, respectively. Both poly( $\varepsilon$-caprolactone) and poly( $\varepsilon$-caprolactone)-dexamethasone solutions were provided at $12 \% \mathrm{~m} / \mathrm{v}$ poly $(\varepsilon$-caprolactone $)$ concentration. 
The incorporation of dexamethasone (5.0 wt.\% regarding the poly ( $\varepsilon$-caprolactone) mass level) promotes thinner fibers for PCL-DEX than control PCL nanofiber mesh (Figure 1). Martins et al. ${ }^{30}$ observed the same behavior for PCL-DEX nanofibers carried out from poly( $\varepsilon$-caprolactone)dexamethasone solutions at $10 \% \mathrm{~m} / \mathrm{v}$ PCL concentration at different dexamethasone contents $(5.0,10,15$ and $20 \mathrm{wt} . \%$ concerning the poly( $\varepsilon$-caprolactone) mass content). These materials were developed from solutions prepared at 70/30 chloroform / dimethylformamide ratio. In this facet, nanofibers display diameters ranging from $150 \mathrm{~nm}$ to $1.6 \mu \mathrm{m} .{ }^{30}$ The addition of only $5.0 \mathrm{wt} . \%$ dexamethasone significantly decreased the PCL-DEX fiber diameter compared to the diameter of the pure PCL membrane. ${ }^{30}$ Here, the dexamethasone-methanol solution added to poly( $\varepsilon$-caprolactone) solution imparts polarity and provides higher elongation on electrospinning jet, allowing thinner fibers for PCL-DEX membrane.

Neutralized PCL-CS electrospun membrane (Figure 1) was developed from a $6.6 \% \mathrm{~m} / \mathrm{v}$ poly( $\varepsilon$-caprolactone) solution containing $20 \mathrm{wt} . \%$ chitosan regarding the whole poly( $\varepsilon$-caprolactone) mass content. This composite is provided from $80 / 20$ poly ( $\varepsilon$-caprolactone) / chitosan mass ratio performed in a 70/30 acetic acid / formic acid mixture. Van der Schueren et al. ${ }^{11}$ prepared PCL-CS fibers by using poly( $\varepsilon$-caprolactone) solutions ranging from 6.0 to $14 \%$ $\mathrm{m} / \mathrm{v}$ and chitosan contents into the poly( $\varepsilon$-caprolactone)based solutions ranging from 15 to $30 \mathrm{wt} \%$. In this case, the chitosan level is established according to the poly( $\varepsilon$ caprolactone) mass content, and nanofibers are also prepared in different acetic acid / formic acid mixtures (70/30, 50/50 and 30/70). Here, PCL-CS nanofiber is developed in an acetic acid excess (70 vol\%).

Comparing the SEM images, it was observed that PCL-CS membrane had the lowest diameter. Chitosan is a cationic polymer $\left(\mathrm{p} K_{\mathrm{a}} 6.5\right)$, which is ionized in an acetic acid / formic acid solution (70/30 volume ratio). Besides, the water content of formic acid (12 vol\%) can increase the conductivity of poly( $\varepsilon$-caprolactone)-chitosan blend, enabling higher elongation on electrospinning jet, inducing formation of thinner fibers.

FTIR spectra for poly( $\varepsilon$-caprolactone)-based composites are depicted in Figure 2. Electrospun PCL-CS and PCL-DEX FTIR spectra were similar to the pure PCL membrane FTIR spectrum. However, for PCL-CS composite, the appearance of a band at $1587 \mathrm{~cm}^{-1}$ is assigned to the $-\mathrm{NH}$ bonds on $-\mathrm{NH}_{2}$ chitosan sites. This signal can also be ascribed to the ionized $-\mathrm{NH}_{3}{ }^{+}$sites that remain on chitosan chains even after PBS neutralization. ${ }^{13}$ Besides, the broadband at $3443 \mathrm{~cm}^{-1}$ is attributed to the $-\mathrm{OH}$ and $-\mathrm{NH}$ stretching, confirming the presence of chitosan in the PCL-CS composite (Figure 2). The small band at $1688 \mathrm{~cm}^{-1}$ in PCL-CS FTIR spectrum may be attributed to the amide groups $(\mathrm{C}=\mathrm{O})$ on chitosan networks. ${ }^{39}$ Chitosan and poly( $\varepsilon$-caprolactone) macromolecules can interact by ion-dipole, H-bonds and by London forces. These effective interactions allow great durability to the PCL-CS composite membrane. Such behavior is confirmed by analyzing the SEM images processed from the dried membranes after incubation of 4 and 7 days into the cell culture medium (Figure 3). After 7 days, all electrospun membranes presented similar morphologies when compared to the asobtained materials (Figure 1).

PCL-DEX membrane FTIR spectrum had no significant changes compared to the PCL FTIR spectrum because of the low dexamethasone content $(5.0 \mathrm{wt} . \%)$. The slight entanglement for the band at $3443 \mathrm{~cm}^{-1}$ in PCL-DEX membrane FTIR spectrum is attributed to the $-\mathrm{OH}$ stretching on the dexamethasone molecules. ${ }^{40}$ Also, the small band at $1688 \mathrm{~cm}^{-1}$ is a characteristic of the $\mathrm{C}=\mathrm{O}$ on dexamethasone structure (Figure 2). ${ }^{30,40}$ On the other hand, dexamethasone does not interact with poly( $\varepsilon$-caprolactone) efficiently. As reported before, poly( $\varepsilon$-caprolactone) membrane promotes a burst release of dexamethasone in PBS. ${ }^{29}$
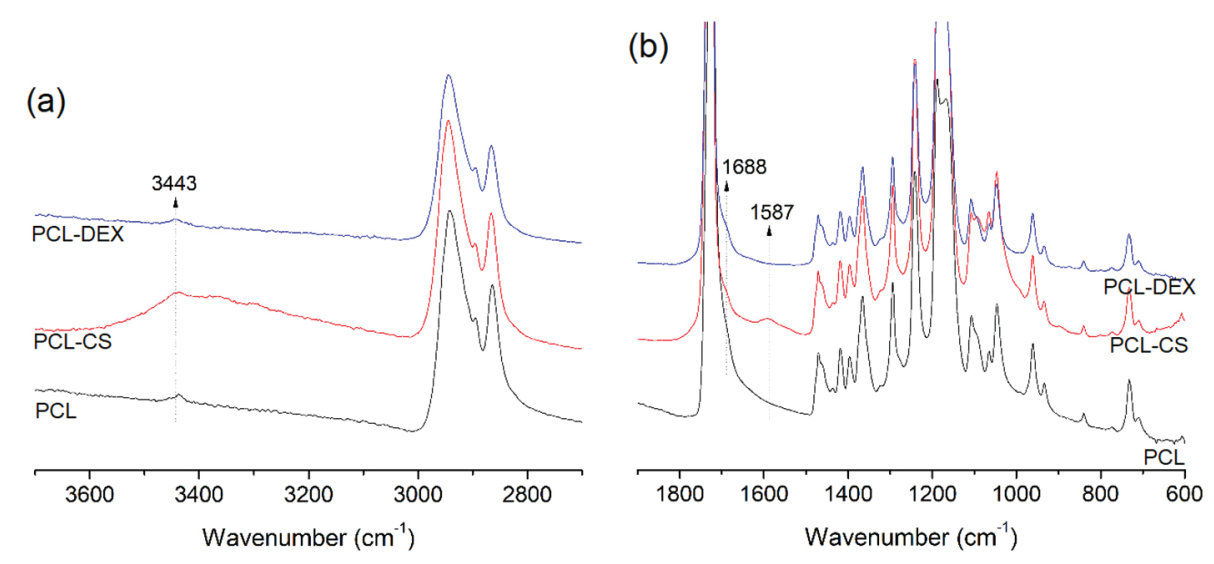

Figure 2. FTIR spectra of the PCL-based electrospun membranes: PCL, PCL-DEX and neutralized PCL-CS. 


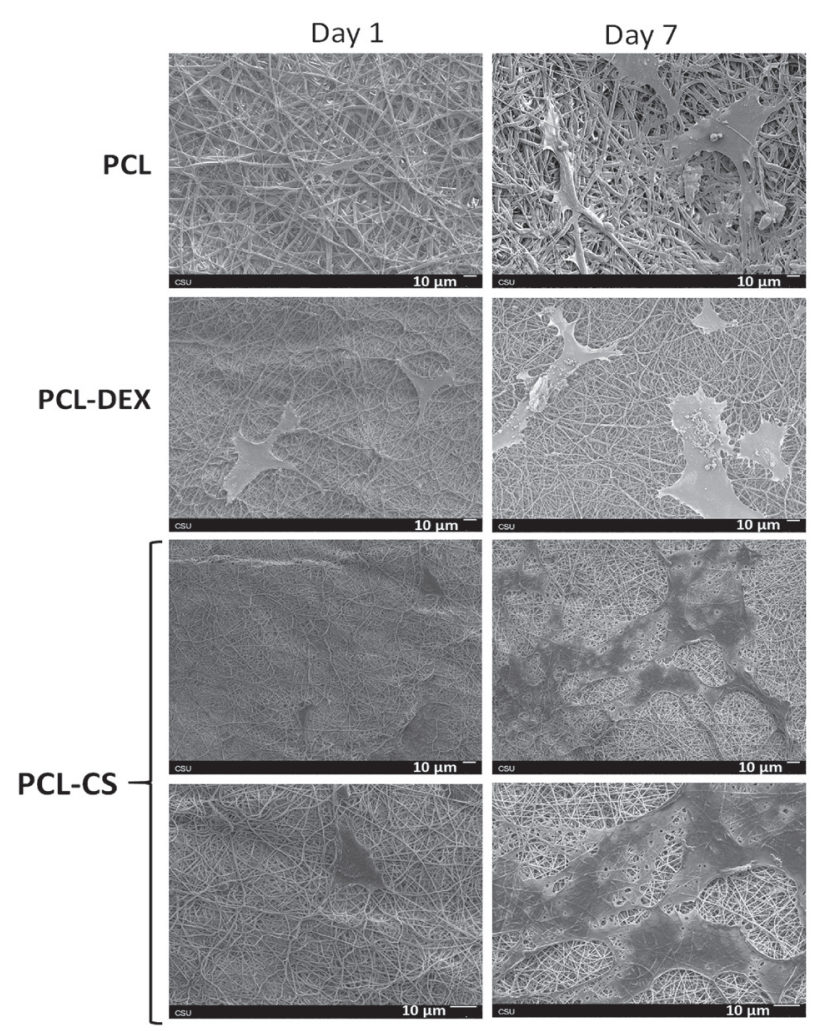

Figure 3. SEM images of the PCL, PCL-DEX and PCL-CS membranes seeded with ADSC cells after 1 and 7 days of culture.

To confirm the presence of dexamethasone into the PCL-DEX membrane, the composition of the PCL and PCL-DEX surfaces was determined by XPS (Figure 4). XPS spectra show a very small peak corresponding to the fluorine at $689 \mathrm{eV}$ (Figure 4). Fluorine is unique to dexamethasone, but it also occurs in the 1,1,1,3,3,3-hexafluoro-2-propanol solvent. For PCL surface, XPS analysis imparted $<0.1 \%$ fluorine because the 1,1,1,3,3,3-hexafluoro-2-propanol remains in the electrospun surface. However, the atomic percentage of fluorine reached $0.5 \%$ in the PCL-DEX surface, indicating the presence of dexamethasone.

(a) PCL

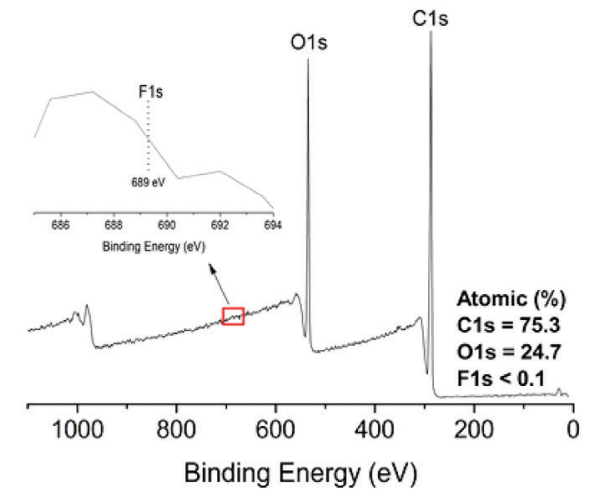

The wettability of different surfaces showed that chitosan and dexamethasone decreased the WCAs for poly( $\varepsilon$-caprolactone)-based membranes (Figure 5). The WCAs are determined throughout $20 \mathrm{~min}$. Measurements indicated that the WCAs significantly reduced after $20 \mathrm{~min}$ by analyzing a water droplet in contact with the electrospun surfaces. For neutralized electrospun PCL-CS, the water droplet was entirely adsorbed after $6.0 \mathrm{~min}$, indicating that the surface is more hydrophilic. However, after $20 \mathrm{~min}$, the WCAs on PCL and PCL-DEX surfaces reported 88 and $48^{\circ}$, respectively. Also, the WCAs depend on the surface area and specific surface properties such as polarity.

Further, the presence of dexamethasone and chitosan imparts smaller WCAs on the poly( $\varepsilon$-caprolactone)-based membranes due to the occurrence of polar chemical groups $\left(-\mathrm{NH}_{2} /-\mathrm{NH}_{3}{ }^{+},-\mathrm{OH},-\mathrm{COOH}\right.$ and $\left.-\mathrm{F}\right)$ on the surfaces. As previously reported, poly( $\varepsilon$-caprolactone)-chitosan composite interacts better with water molecules when compared to the pure poly( $\varepsilon$-caprolactone) ${ }^{22}$ However, PCL-DEX mainly provided lower WCAs than PCL membrane because PCL-DEX exhibited thinner fibers. Dexamethasone is a hydrophobic drug, but the different average size of the membranes can induce changes in the WCA measurements. For poly( $\varepsilon$-caprolactone)-based membranes, the fiber diameters should influence the contact angle measurements because PCL has high hydrophobicity. Also, the presence of dexamethasone should slightly increase the surface wettability of the PCL membrane because it has hydrophilic moieties in its structure $(-\mathrm{OH}$, $-\mathrm{COOH}$ and $-\mathrm{F}$ ).

Dexamethasone release and cell viability assay

Dexamethasone release curve profile is presented in Figure S1 (SI section). As reported elsewhere, ${ }^{29,30}$ there are no effective intermolecular interactions between dexamethasone and poly( $\varepsilon$-caprolactone) electrospun

(b) PCL-DEX

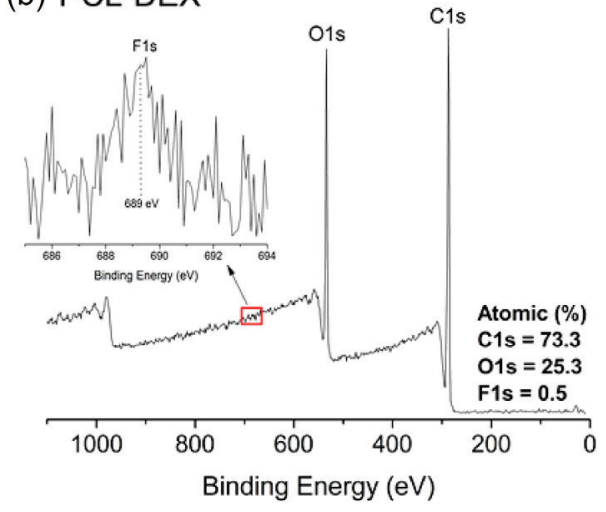

Figure 4. XPS spectra: PCL (a) and PCL-DEX membrane surfaces (b). 


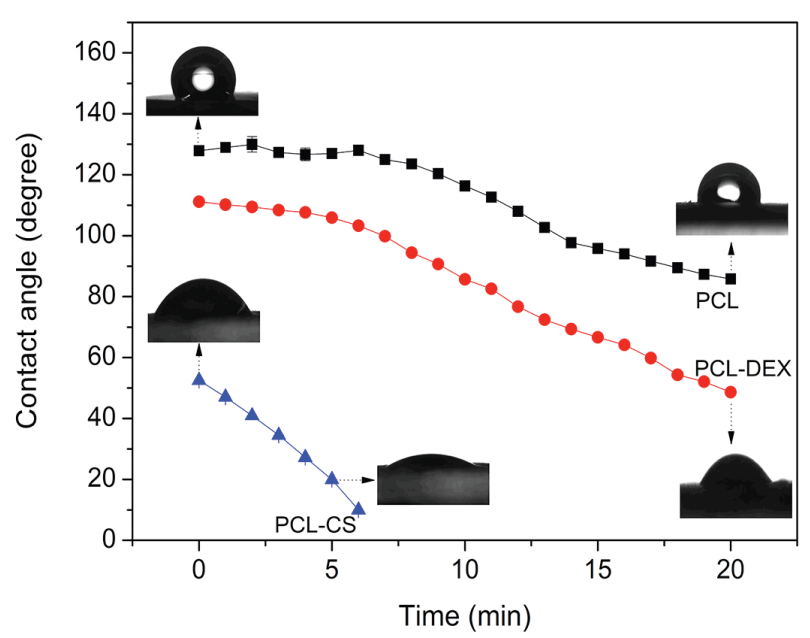

Figure 5. Contact angle measurements on the PCL, PCL-DEX and PCL-CS membrane surfaces.

membranes. Then, a weaker association promotes the burst release of dexamethasone from the pure poly ( $\varepsilon$-caprolactone) electrospun membrane. The released fraction achieves ca. 1.0 after only $120 \mathrm{~min}$ in PBS at $37^{\circ} \mathrm{C}$ (Figure S1, SI section). Therefore, the biological response of the poly(e-caprolactone) loaded with dexamethasone should mainly be attributed to the released content of dexamethasone into the cell culture medium. Before cell culture assay, the PCL-CS membrane is washed in PBS (pH 7.4) because a current study showed that the washing step performed with PBS is a better approach when compared to a diluted weak base ammonium hydroxide solution. ${ }^{34}$

The cytotoxicity of the PCL and PCL-based composites can be determined from the CellTiter-Blue ${ }^{\circledR}$ assay kit. This kit comprises resazurin, a non-toxic and cell permeable dye that acts as a fluorescent blue indicator. Resazurin indicates a color change from blue to pink, in response to the reduction of cellular metabolic activity and its fluorescence intensity depends on the number of living cells..$^{41}$ The cell

(a)

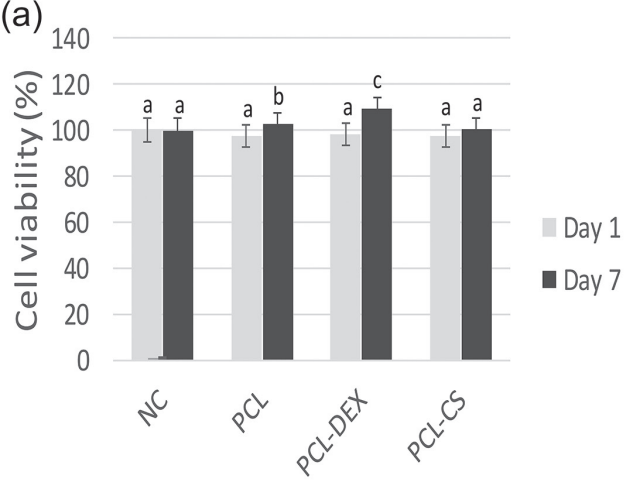

viability assay revealed that ADSC cells remained viable on all samples in 7 days of culture (Figure 6a). However, after 7 days, PCL-DEX composite promoted the highest cell viability (109\%), followed by PCL (103\%) and PCL-CS (100\%) membranes. Here, even in a low dexamethasone level (5.0 wt.\%), the PCL-DEX fosters higher cell viability onto the ADSC cells than PCL-CS electrospun in a high chitosan content (20 wt.\%). However, dexamethasonebased materials have disadvantages for biomedical purposes because of their side effects promoted to the body. ${ }^{17,18}$ The PCL-CS membrane provided a similar result for cell viability when compared to the negative control (NC) (Figure 6a). The NC is based on an experiment with cells seeded without presence of membranes. All the composites are cytocompatible to ADSC cells, and they can act as scaffolds for skin engineering purposes.

\section{Adhesion and proliferation test}

Results of cell counts indicate that PCL-DEX and PCL-CS nanofibers promote significant anchorage, adhesion, and proliferation of ADSC cells in their surfaces when compared to the PCL surface (Figure 6b). Cells are seeded at a very low density (5000 per well). For each sample $(n=3)$, the number of adhered cells is counted and then summed over ten non-overlapping fields of view of the microscope (at 20x). After day 1, the number of attached cells on the PCL, PCL-DEX, and PCL-CS membranes were 87, 206 and 189, respectively (Figure 6b). Sequentially, after day 7 of culture, the number of anchored cells increased to 164, 238 and 234 (Figure 6b). In the same period of culture, PCL and PCL-CS membranes impart a higher increase for cell proliferation than PCL-DEX surface. However, after day 7 , there is no statistical difference between the cell proliferation results provided for PCL-DEX and PCL-CS membranes (Figure 6b). These

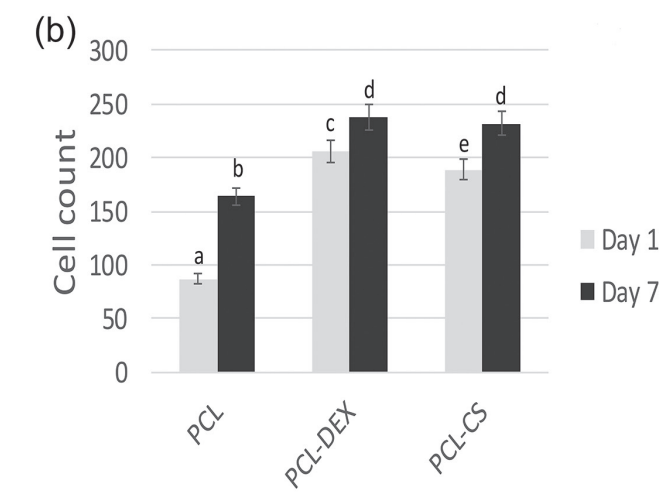

Figure 6. (a) Cell viabilities of ADSC cells promoted for PCL, PCL-DEX, and neutralized PCL-CS membranes after 1 and 7 days of cell culture. Negative control (NC): assay carried out only with cells and without membrane samples. (b) Quantification of ADSC cell proliferation on PCL, PCL-DEX and neutralized PCL-CS membrane after 1 and 7 days of culture. Statistically significant differences can be observed among groups with different superscript letters $(p<0.05)$. 
findings have agreed with other reported results. Chitosan improves the surface wettability, enhancing the attachment and proliferation of cells on the poly( $\varepsilon$-caprolactone)-based nanofibers. ${ }^{22,28}$ A chitosan content of 30 wt. $\%$ decreased the contact angle on poly( $\varepsilon$-caprolactone) surface from 123 to $41^{\circ} .{ }^{22}$ As expected, the synthetic glucocorticoid dexamethasone fosters cell proliferation onto the poly( $\varepsilon$-caprolactone) membrane, mainly because of its renowned anti-inflammatory properties. ${ }^{29,30}$

Cell attachment and proliferation outcomes are supported by analyzing the fluorescence microscopy and SEM images (Figures 7 and 3, respectively). PCL-CS and PCL-DEX membranes promoted proliferation of ADSC cells because after day 7 there are many more attached cells on PCL-CS and PCL-DEX surfaces (Figure 7). However, the cells are more flattened and spread on PCL-CS surface. The size diameter of the nanofibers can also influence the cell culture results because of the surface area. SEM images revealed that PCL-CS membrane permits better spreading for ADSC cells after 7 days of culture, imparting formation of ADSC cell tissues on the composite surface (Figure 3). This behavior was not observed on PCL and PCL-DEX electrospun membranes (Figure 3). Even more, following attachment, the formation of new bonds and establishment of novel interactions occur between cell surface receptors and PCL-CS membrane, allowing cell adhesion and better cell spreading. The cytoskeletal reorganization permits cell spreading onto the PCL-CS membrane, increasing the strength of cell attachment.

Dexamethasone is a well-known drug due to its capacity to stimulate proliferation of mesenchymal stem

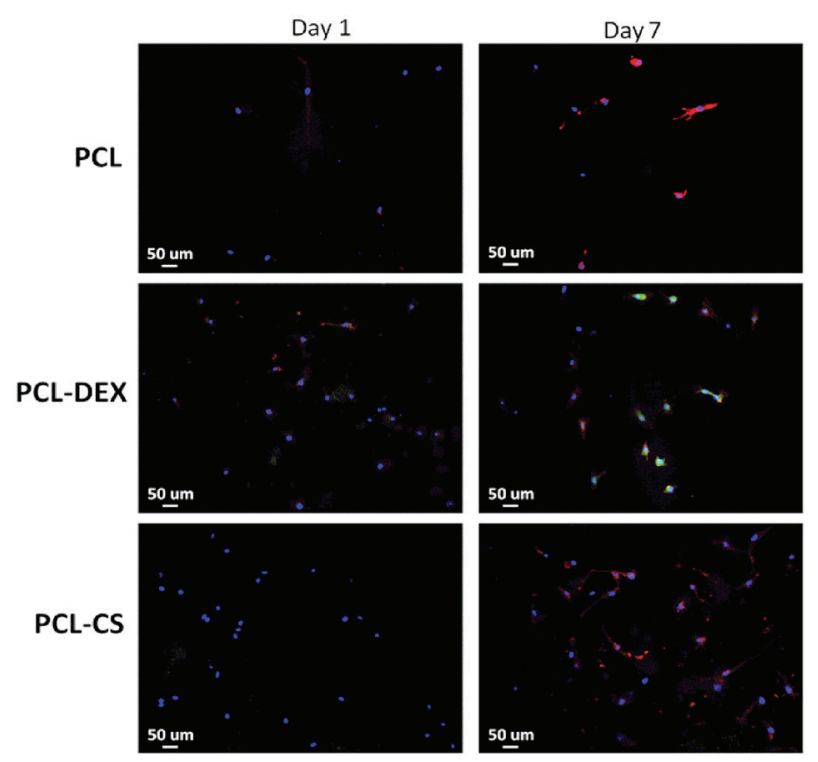

Figure 7. Fluorescence microscopy images $(20 \times)$ of the PCL, PCL-DEX and PCL-CS membranes seeded with ADSC cells after 1 and 7 days of culture. cells, ${ }^{30}$ and because of its anti-inflammatory properties. ${ }^{7}$ Dexamethasone has been used to treat cancer, ${ }^{42}$ skin diseases, ${ }^{43}$ acute bacterial meningitis, ${ }^{44}$ and other diseases. Also, dexamethasone can be used for local anesthetic pain relief therapy; ${ }^{45}$ however, skin atrophy is accelerated by topical dexamethasone treatments, which is widely used in dermatology. Gebhardt et al. ${ }^{46}$ showed that dermal hyaluronan in human skin is reduced after short-term dexamethasone treatments, imparting skin atrophy. In the treatment of acute lymphoblastic leukemia, dexamethasone has promoted adverse effects such as infection, bone fracture, osteonecrosis, and myopathy. ${ }^{47}$ Therefore, new alternative materials (like PCL-CS membrane) that overcome these disadvantages are essential.

\section{Antimicrobial assay}

Figure 8 depicts the antimicrobial activity of the PCL-DEX and PCL-CS membranes against $P$. aeruginosa. The number of live / dead cells is counted and then summed over five non-overlapping fields of view of the microscope (at 100x). For each sample, three samples $(n=3)$ are used for each condition at each time point. The PCL-CS composite promotes a strong antimicrobial activity (ca. $90 \%$ inhibition after $24 \mathrm{~h}$ ), while the PCL-DEX surface provides only $18 \%$ death. The antimicrobial activity of PCL-CS material is attributed to the remaining $-\mathrm{NH}_{3}{ }^{+}$ sites $(401.2 \mathrm{eV})^{48}$ on the PCL-CS surface even after PBS neutralization (Figure 9). This fact was confirmed by XPS analysis. Cationic sites on PCL-CS can interact with $P$. aeruginosa cell walls (negatively charged), increasing cell permeability, allowing leakage of cell constituents and cell death. ${ }^{49}$

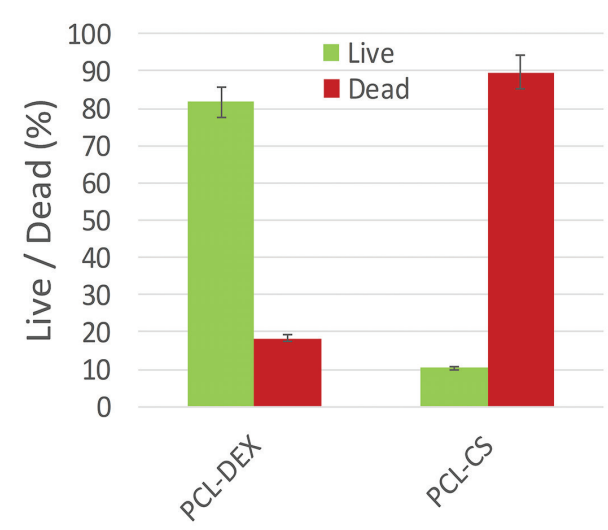

Figure 8. Antimicrobial activity of the PCL-DEX and neutralized PCL-CS membranes after $24 \mathrm{~h}$ of incubation with $P$. aeruginosa.

Chitosan and quaternized ammonium chitosan derivatives have received attention because of their renewed antimicrobial activity against several bacteria types. ${ }^{49,50}$ 

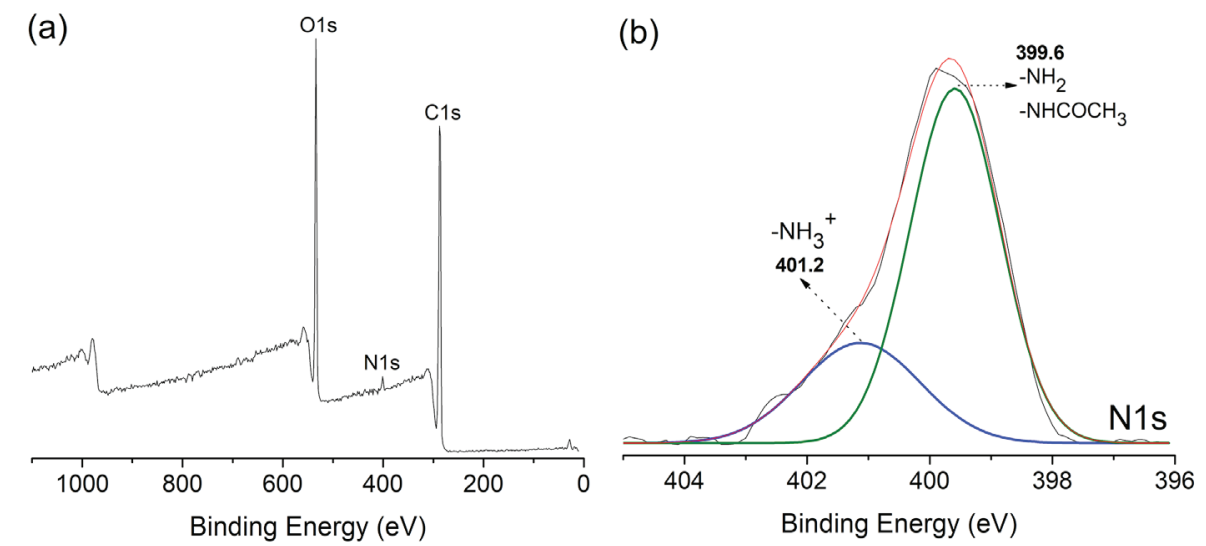

Figure 9. XPS spectra of the neutralized PCL-CS membrane: survey (a) and high-resolution XPS spectrum for N1s (b).

Also, some works have related that dexamethasone and some dexamethasone-based derivatives present antimicrobial action. ${ }^{51,52}$ However, for treating skin diseases, dexamethasone is usually administrated with gentamycin (an antibiotic with strong antimicrobial activity that provides an acute kidney injury). ${ }^{18,53}$ Dexamethasone and antibiotics cause several side effects on health. Therefore, the antimicrobial activity of the PCL-CS electrospun membrane is important since this biomaterial can be used as a scaffold for skin regeneration and in contact with skin tissues it may avoid infection promoted by $P$. aeruginosa. So, this material can be used to treat skin diseases.

\section{Conclusions}

This study indicates for the first time that a PCL-CS membrane seeded with ADSCs (human cells) may promote better conditions for mesenchymal stem cell survival than PCL-DEX membrane. Chitosan imparts better biological responses than dexamethasone for poly ( $\varepsilon$-caprolactone)based membranes. Here, the chitosan content (20 wt.\%) can be tuned on a PCL-based membrane to promote at least similar results for anchorage, adhesion and proliferation of ADSC cells, when compared to the PCLDEX material loaded with $5.0 \mathrm{wt} . \%$ dexamethasone. However, PCL-CS electrospun membrane can be used as a scaffold material for skin regeneration and to treat skin diseases instead of conventional strategies based on dexamethasone approaches because of the side effects promoted on health.

\section{Supplementary Information}

Supplementary data are available free of charge at http://jbcs.sbq.org.br as PDF file.

\section{Acknowledgments}

A. F. M. thanks Conselho Nacional de Desenvolvimento Científico e Tecnológico (CNPq) for financial support (protocols 0008678964988973 and 6143236324614401 ). This study was financed in part by the Coordenação de Aperfeiçoamento de Pessoal de Nível Superior - Brasil (CAPES)-Finance Code 001.

\section{References}

1. Ruckh, T. T.; Kumar, K.; Kipper, M. J.; Popat, K. C.; Acta Biomater. 2010, 6, 2949.

2. Gomes, S.; Rodrigues, G.; Martins, G.; Henriques, C.; Silva, J. C.; Int. J. Biol. Macromol. 2017, 102, 1174.

3. Hong, S.; Kim, G.; Carbohydr. Polym. 2011, 83, 940.

4. Trinca, R. B.; Westin, C. B.; da Silva, J. A. F.; Moraes, Â. M.; Eur. Polym. J. 2017, 88, 161.

5. Komur, B.; Bayrak, F.; Ekren, N.; Eroglu, M. S.; Oktar, F. N.; Sinirlioglu, Z. A.; Yucel, S.; Guler, O.; Gunduz, O.; Biomed. Eng. Online 2017, 16, 40.

6. Costa, P. F.; Puga, A. M.; Díaz-Gomez, L.; Concheiro, A.; Busch, D. H.; Alvarez-Lorenzo, C.; Int. J. Pharm. 2015, 496, 541.

7. Li, Y.-F.; Rubert, M.; Yu, Y.; Besenbacher, F.; Chen, M.; RSC Adv. 2013, 5, 34166.

8. Tentor, F. R.; de Oliveira, J. H.; Scariot, D. B.; Lazarin-Bidóia, D.; Bonafé, E. G.; Nakamura, C. V.; Venter, S. A. S.; Monteiro, J. P.; Muniz, E. C.; Martins, A. F.; Int. J. Biol. Macromol. 2017, 102, 1186.

9. Facchi, D. P.; Cazetta, A. L.; Canesin, E. A.; Almeida, V. C.; Bonafé, E. G.; Kipper, M. J.; Martins, A. F.; Chem. Eng. J. 2018, 337, 595.

10. Facchi, D. P.; da Cruz, J. A.; Bonafe, E. G.; Pereira, A. G.; Fajardo, A. R.; Venter, S. A.; Monteiro, J. P.; Muniz, E. C.; Martins, A. F.; Curr. Med. Chem. 2017, 24, 2701.

11. Van der Schueren, L.; Steyaert, I.; de Schoenmaker, B.; de Clerck, K.; Carbohydr. Polym. 2012, 88, 1221. 
12. Shalumon, K. T.; Anulekha, K. H.; Girish, C. M.; Prasanth, R.; Nair, S. V.; Jayakumar, R.; Carbohydr. Polym. 2010, 80, 414.

13. Cooper, A.; Bhattarai, N.; Zhang, M.; Carbohydr. Polym. 2011, 85, 149.

14. Rodrigues, A.; Gomes, A.; Marçal, P. H. F.; Dias-Souza, M. V.; J. Adv. Res. 2017, 8, 55.

15. Gales, A. C.; Castanheira, M.; Jones, R. N.; Sader, H. S.; Diagn. Microbiol. Infect. Dis. 2012, 73, 354.

16. Goldenberg, D.; Golz, A.; Netzer, A.; Joachims, H. Z.; Am. J. Otolaryngol. 2002, 23, 142.

17. Klewicka, E.; Cukrowska, B.; Libudzisz, Z.; Ślizewska, K.; Motyl, I.; Pol. J. Microbiol. 2011, 60, 329.

18. Hayward, R. S.; Harding, J.; Molloy, R.; Land, L.; LongcroftNeal, K.; Moore, D.; Ross, J. D. C.; Br. J. Clin. Pharmacol. 2018, 84, 223.

19. Vardy, J.; Chiew, K. S.; Galica, J.; Pond, G. R.; Tannock, I. F.; Br. J. Cancer 2006, 94, 1011.

20. Zhou, Z.; Yan, H.; Liu, Y.; Xiao, D.; Li, W.; Wang, Q.; Zhao, Y.; Sun, K.; Zhang, M.; Lu, M.; Regener. Med. 2018, 13, 331.

21. Abuelreich, S.; Manikandan, M.; Aldahmash, A.; Alfayez, M.; Al Rez, M. F.; Fouad, H.; Hashem, M.; Ansari, S. G.; Al-Jassir, F. F.; Mahmood, A.; J. Nanosci. Nanotechnol. 2017, 17, 1771.

22. Sadeghi, A.; Moztarzadeh, F.; Aghazadeh Mohandesi, J.; Int. J. Biol. Macromol. 2019, 121, 625.

23. Hokmabad, V. R.; Davaran, S.; Aghazadeh, M.; Alizadeh, E.; Salehi, R.; Ramazani, A.; Tissue Eng. Regener. Med. 2018, 15, 735.

24. Gholipour-Kanani, A.; Samadikuchaksaraei, A.; Mohsenzadegan, M.; Fayyazi, M.; Mater. Today: Proc. 2018, 5,15629 .

25. Ehterami, A.; Salehi, M.; Farzamfar, S.; Vaez, A.; Samadian, H.; Sahrapeyma, H.; Mirzaii, M.; Ghorbani, S.; Goodarzi, A.; Int. J. Biol. Macromol. 2018, 117, 601.

26. Gholipour-Kanani, A.; Mohsenzadegan, M.; Fayyazi, M.; Bahrami, H.; Samadikuchaksaraei, A.; IET Nanobiotechnol. 2018, 12, 619.

27. Rodríguez-Méndez, I.; Fernández-Gutiérrez, M.; RodríguezNavarrete, A.; Rosales-Ibáñez, R.; Benito-Garzón, L.; VázquezLasa, B.; Román, J. S.; Polymers 2018, 10, 279.

28. Li, H.; Hu, C.; Yu, H.; Chen, C.; RSC Adv. 2018, 8, 3736.

29. Vacanti, N. M.; Cheng, H.; Hill, P. S.; Guerreiro, J. D. T.; Dang, T. T.; Ma, M.; Watson, S.; Hwang, N. S.; Langer, R.; Anderson, D. G.; Biomacromolecules 2012, 13, 3031.

30. Martins, A.; Duarte, A. R. C.; Faria, S.; Marques, A. P.; Reis, R. L.; Neves, N. M.; Biomaterials 2010, 31, 5875.

31. Urbanek, O.; Sajkiewicz, P.; Pierini, F.; Polymer 2017, 124, 168.

32. de Oliveira, A. C.; Vilsinski, B. H.; Bonafé, E. G.; Monteiro, J. P.; Kipper, M. J.; Martins, A. F.; Int. J. Biol. Macromol. 2019 , $128,114$.
33. Martins, J.; Oliveira, A.; Garcia, P.; Kipper, M.; Martins, A.; Carbohydr. Polym. 2018, 188, 136.

34. Martins, A. F.; Facchi, S. P.; da Câmara, P. C. F.; Camargo, S. E. A.; Camargo, C. H. R.; Popat, K. C.; Kipper, M. J.; J. Colloid Interface Sci. 2018, 525, 21.

35. Schneider, C. A.; Rasband, W. S.; Eliceiri, K. W.; Nat. Methods 2012, 9, 671.

36. Martins, J. G.; Camargo, S. E. A.; Bishop, T. T.; Popat, K. C.; Kipper, M. J.; Martins, A. F.; Carbohydr. Polym. 2018, 197, 47.

37. GraphPad Software Inc.; GraphPad Prism 6.0; GraphPad Software Inc., USA, 2013.

38. Hild, M.; Al Rez, M. F.; Aibibu, D.; Toskas, G.; Cheng, T.; Laourine, E.; Cherif, C.; Autex Res. J. 2015, 15, 54.

39. Senda, T.; He, Y.; Inoue, Y.; Polym. Int. 2002, 51, 33.

40. Nadim, A.; Khorasani, S. N.; Kharaziha, M.; Davoodi, S. M.; Mater. Sci. Eng., C 2017, 78, 47.

41. Pulyala, P.; Singh, A.; Dias-Netipanyj, M. F.; Cogo, S. C.; Santos, L. S.; Soares, P.; Gopal, V.; Suganthan, V.; Manivasagam, G.; Popat, K. C.; Mater. Sci. Eng., C 2017, 75, 1305.

42. Palamà, I. E.; Arcadio, V.; D’Amone, S.; Biasiucci, M.; Gigli, G.; Cortese, B.; Sci. Rep. 2017, 7, 12672.

43. Marchionni, A. M. T.; Medrado, A. P.; Silva, T. M. C.; Fracassi, L. D.; Pinheiro, A. L. B.; Reis, S. R. A.; Photomed. Laser Surg. 2010, 28, 639 .

44. Schultz, B. R.; Allen, C. H.; Kaplan, S. L.; Ann. Emerg. Med. 2009, 54, 136.

45. Zhang, Y.; Yue, Y.; Chang, M.; Biomed. Pharmacother. 2017, $96,443$.

46. Gebhardt, C.; Averbeck, M.; Diedenhofen, N.; Willenberg, A.; Anderegg, U.; Sleeman, J. P.; Simon, J. C.; J. Invest. Dermatol. 2010, 130, 141.

47. Inaba, H.; Pui, C.-H.; Lancet Oncol. 2010, 11, 1096.

48. Romero, R.; Chubb, L.; Travers, J. K.; Gonzales, T. R.; Ehrhart, N. P.; Kipper, M. J.; Carbohydr. Polym. 2015, 122, 144.

49. Martins, A. F.; Facchi, S. P.; Follmann, H. D. M.; Pereira, A. G. B.; Rubira, A. F.; Muniz, E. C.; Int. J. Mol. Sci. 2014, 15,20800 .

50. Follmann, H. D. M.; Martins, A. F.; Nobre, T. M.; Bresolin, J. D.; Cellet, T. S. P.; Valderrama, P.; Correa, D. S.; Muniz, E. C.; Oliveira, O. N.; Carbohydr. Polym. 2016, 137, 418.

51. Neher, A.; Arnitz, R.; Gstöttner, M.; Schäfer, D.; Kröss, E. M.; Nagl, M.; Arch. Otolaryngol., Head Neck Surg. 2008, 134, 615.

52. Bucki, R.; Leszczyńska, K.; Byfield, F. J.; Fein, D. E.; Won, E.; Cruz, K.; Namiot, A.; Kułakowska, A.; Namiot, Z.; Savage, P. B.; Diamond, S. L.; Janmey, P. A.; Antimicrob. Agents Chemother. 2010, 54, 2525.

53. El Amir, A. M.; Tanious, D. G.; Mansour, H. A.; Int. Immunopharmacol. 2017, 52, 176.

Submitted: December 18, 2018

Published online: April 30, 2019 